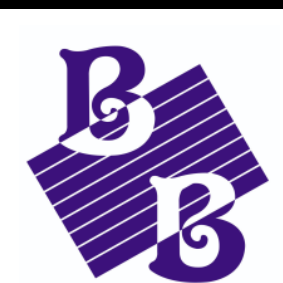

BioBacta

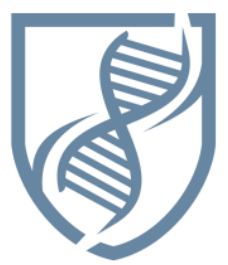

Journal of Bioscience and Applied Research www.jbaar.org

\title{
A Theory of Biodiversity and Gene Evolution
}

\author{
Sobhy E. Hassab El-Nabi \\ Zoology Department - Faculty of Science Menufia University- Egypt \\ DOI: 10.21608/jbaar.2020.122477
}

\begin{abstract}
The statement of theory: \{Evolution of organisms and biodiversity depends mainly on gene evolution through the appearance of novel genes. Biodiversity results from the DNA modifications induced by visible and non-visible environmental effects, the variation of gene expression, stresses, mutation, and invasion of genetic materials. Each individual belongs to the same species of living organisms has its own identity of DNA fingerprint $\}$. The principles of theory: Gene evolution depends mainly on gene duplication, a variety of environmental conditions, mutation, transposable elements, horizontal gene transfer (HGT). Also, de nove genes originated from non-coding DNA which mainly comes from retroviruses, exosome, micro-RNA, and invader nucleic acids from viruses, bacteria, or any parasite. Similarity and variations are the principles of life. In the same species, the similarity is produced from coding DNA while, individual variations arise from noncoding DNA. Aim and applications of theory: The main prediction of this theory is not only each individual of human beings have his unique DNA fingerprint, but also any individual in the same species has also a unique identity in DNA fingerprint. Any living organism acquires genetic materials through their intimate contacts with other organisms and environmental DNA. If the acquired genetic material reaches germ cells, it could transfer to the next generation giving new traits. Viruses are considered the main source of genetic transformation in all living organisms. The genomic materials of some viruses could integrate inside the human genome like hepatitis B and HIV. The human genome has about $5 \%$ viral genetic material, especially from retroviruses. This theory could explain the appearance of new individuals according to the transfer of genetic materials during intimate contact between different species and support many researchers who discovered new species. Also, this theory may explain and will answer different questions; why husband and wife after some time, nearly acquire some similarities? Why people in the same geographical area nearly have a similar pattern? Why don't siblings match their DNA fingerprint? Also, it explains the host-parasite relationship depending upon the transfer of DNA and RNA in between.
\end{abstract}

Kew words: Evolution; biodiversity; gene evolution; environmental stressors; DNA; micro-RNA; SNP; horizontal gene transfer; de nove genes; molecular evolution 


\section{Introduction}

Although the human afraid from variations, the creation depends upon integrated variation. The environment and genetic materials are responsible for biodiversity and evolution. Environmental stressors (visible and non-visible things) including, pollutions including, chemicals and biomaterials such as viruses, bacteria fungi, and environmental DNA or invader DNA lead to DNA modifications that result in biodiversity and $+/$ - microevolution. This theory is used and applied to explain the emergence of new types of organisms through generating new genes, gene duplication, horizontal gene transfer (HGT), transposable elements, +/mutation, and DNA polymorphisms to resist various environmental stressors. Also, this theory explains some phenomena, such as the convergence or similarities of a husband and his wife, also, the similarity among all residents of an ethnic group that resides in one region by transporting the microRNA from vegetables, foods, and biological fluids. Moreover, the theory also explains the difference of siblings in their genetic fingerprint through the variation in the process of linkage and crossing over that occurs during the meiosis division. In addition,

it illustrates the relationship between host and parasite that depends on the transfer of DNA and RNA in between them. The central dogma of biodiversity and evolution \{environmental effects on the genetic material (DNA) of living organisms lead to modifications of DNA and these modifications lead to biological diversity and $+/$ micro-evolution \} were designed based on the current theory. The theory clarifies the relationship between evolution and adaptation, as any adaptation or modification is considered +/- micro-evolution. The definition of evolution unit, which is the permanent change or modification in one base pair in the entire individual genome compared to its previous ancestor was identified. The theory provides an explanation of the haplotype dendogram, the single nucleotide polymorphism (SNP), and clarifying that each point on the line between clades considered as one evolution unit. The evolution can be measured quantitatively according to this formula: Degree of evolution = numbers of + micro-evolution unit (Hassab El-Nabi, 2016; Hassab El-Nabi 2020; Hassab El-Nabi et al. 2020).

\section{Previous works supported the proposed theory}

Evolution is the change of inherited characteristics within a population over time through natural selection, which may result in the formation of a new species. Lamarck's theory, at the beginning of the 19th century Jean-Baptiste Lamarck was a French scientist who developed an alternative theory of evolution before Charles Darwin. Lamarck's theory involved two ideas: A characteristic that is used more and more by an organism becomes bigger and stronger, and one that is not used eventually disappears. Any feature of an organism that is improved through use is passed to its offspring. However, through modern science, we now know that in the vast majority of cases this type of inheritance cannot occur. Lamarck's theory cannot account for all the observations made about life on Earth. For instance, his theory implies that all organisms would gradually become complex, and simple organisms disappear.

Lamarck argues that life was not fixed. When environments changed, organisms had to change their behavior to survive. If they began to use an organ more than they had in the past, it would increase in its lifetime. If a giraffe stretched its neck for leaves, for example, a "nervous fluid" would flow into its neck and make it longer. Its offspring would inherit the longer neck, and continued stretching would make it longer still over several generations. Meanwhile, organs that organisms stopped using would shrink (Ghiselin, Michael T. (1994).

Charles Darwin was a British naturalist who proposed the theory of biological evolution by natural selection. Darwin defined evolution as "descent with modification," the idea that species change over time, 
give rise to new species and share a common ancestor. The mechanism that Darwin proposed for evolution is natural selection. Darwin also suggested a mechanism for evolution: natural selection, in which heritable traits that help organisms survive and reproduce become more common in a population over time. Traits are often heritable. In living organisms, many characteristics are inherited, or passed from parent to offspring (Darwin Charles 1859; Huxley, T.H. 1860). Darwin knew this was the case, even though he did not know that traits were inherited via genes.

Recent attempts to reconcile neo-Darwinism and neo-Lamarckism in a unified theory of molecular evolution give epigenetic mechanisms and microbiome a prominent role. However, supporting empirical data is still largely missing. Because experimental studies using extant animals can hardly be done over evolutionary timescales. Liu et al.
(2019) proposed that advances in ancient DNA techniques provide a valid alternative, so novel dynamics in animal evolution and adaptation can be revealed. Also, they evaluate: (1) the possible roles of epigenomes and microbiomes in animal adaptation; (2) advances in the retrieval of paleoepigenome and paleomicrobiome data using ancient DNA techniques; and (3) the plasticity of either and interactions between the epigenome and the microbiome, (Liu et al.,2019).

The theory of evolution and diversity of living organisms is not only explained on the morphological characters (Phenotype) but also on genetic characters (genotype) through gene evolution. The flow of genetic information starts from the gene through the transcription process that produces mRNA which is then translated to a protein on ribosomes through the translation process (Fig. 1).

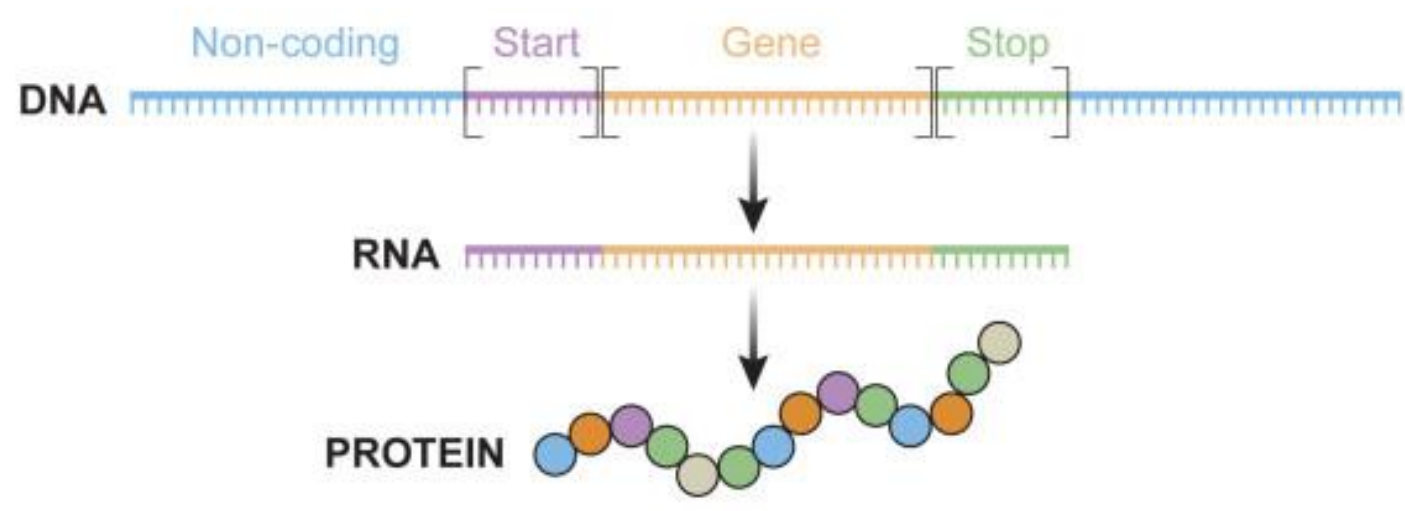

\section{Fig. (1) The central dogma - DNA encodes RNA, which in turn is translated into proteins. Image@Edvotek 2014}

Several mechanisms frequently cooperate in generating a new gene (Fig. 2) through exon or domain shuffling, gene duplication, retrotransposition, transposon elements (TE) domestication, lateral gene transfer, gene fission or fusion, de novo origination, reading -frame shift, alternative splicing, non-coding RNA and pseudogenes as RNA regulator. 

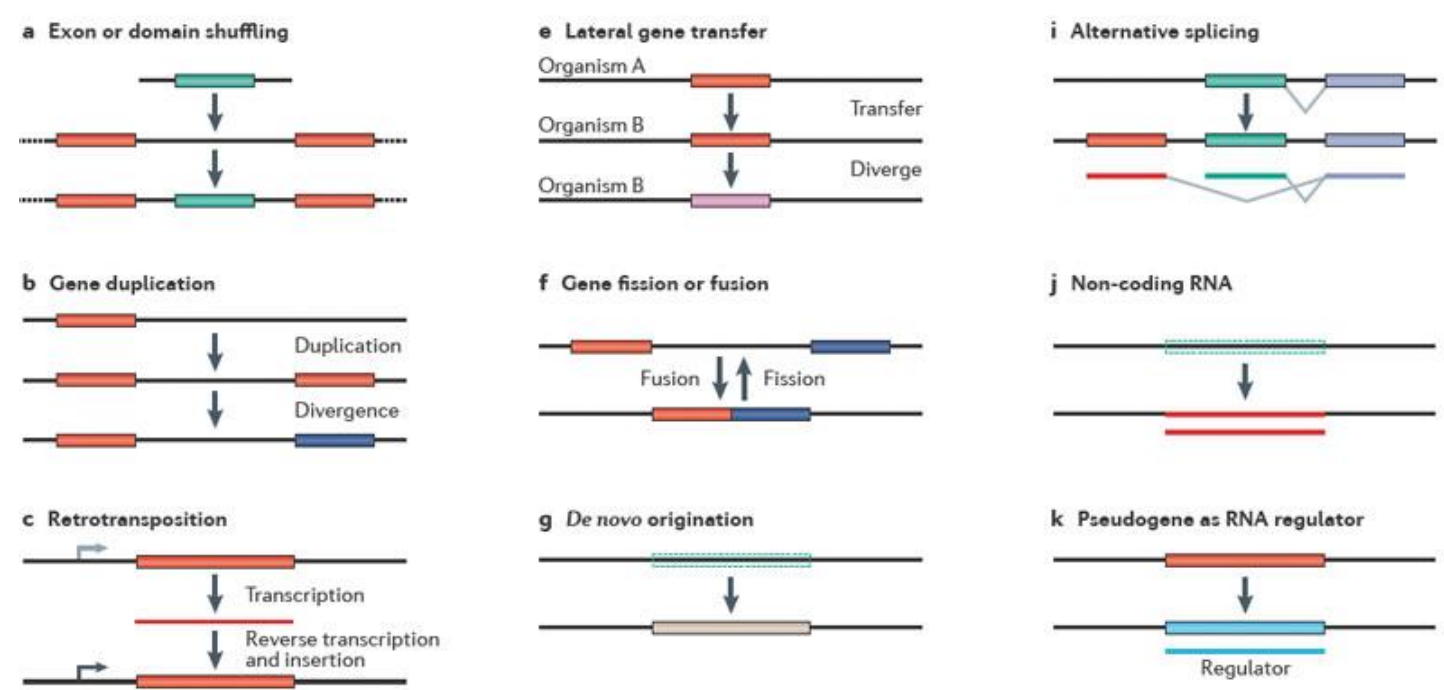

j Non-coding RNA
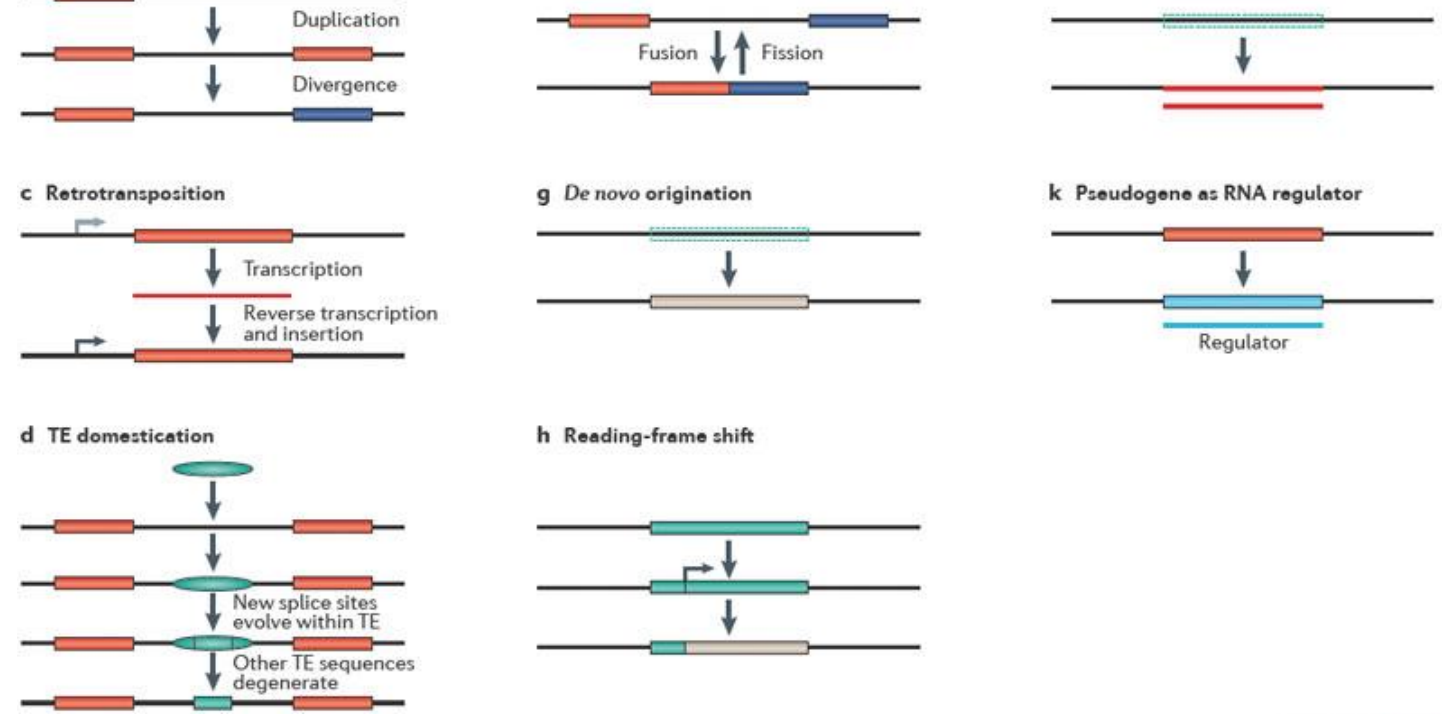

h Reading-frame shift

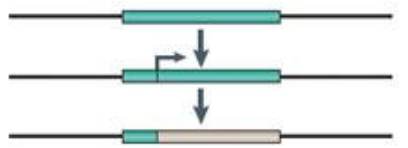

Fig. (2) Different mechanisms explain the development of new genes (after Sidi et al., 2013)

DNA is responsible for the continuity of life due to its ability to be replicated. If this molecule loses this character and the replication process stops, the biological life disappears on the earth, because of cell division, growth, reproduction formation of embryos. Some genetic materials transfer in the same genome through transposable elements or from one organism to another naturally through horizontal gene transfer (HGT) or artificially through genetic engineering techniques. Hence, forming transformed organisms or transgenic animals will stop. DNA is considered as book of the life for each organism. Life is based on identity and diversity, it starts with identity then gene evolution leads to diversity, then return back to identity for each newborn individual.

Understanding how genes originated and subsequently evolve is crucial for explaining the genetic basis for the origin and evolution of novel phenotypes and, ultimately, biological diversity (Manyuan et al., 2013). Mutation of any gene (Fig. 3) in a germ cell leads to the formation of a proto-gene. This proto-gene structure must then spread through the population until it becomes fixed. To form new a gene, about 5 mechanisms to be done. 


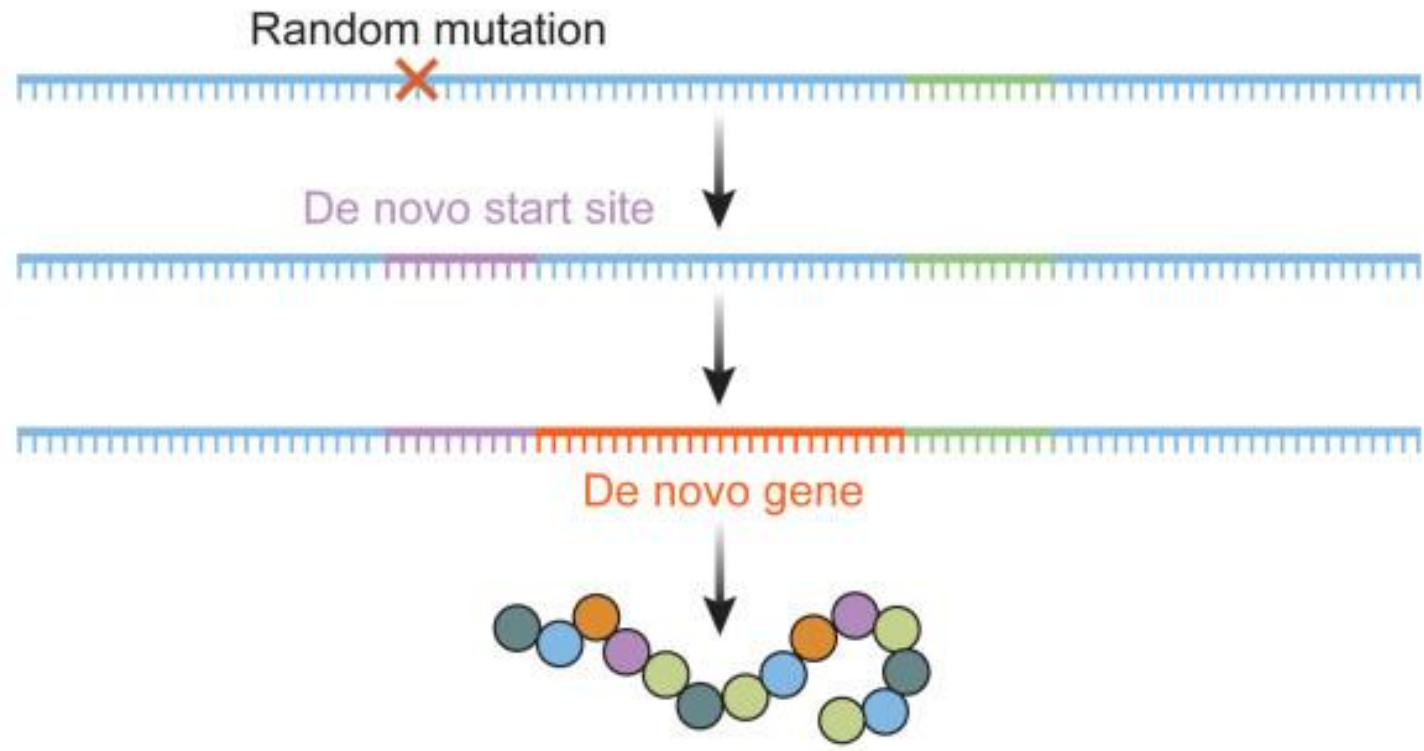

Fig. (3) The de novo formation of a gene. A random mutation leads to the creation of a new start site within a non-coding region of DNA, resulting in the formation of a new gene. Image CEdvotek 2014.

The first one is gene duplication which is thought to contribute most to the generation of new genes. A single or few new gene structure(s) can be formed at one time by DNA - based duplication (the copying and pasting of DNA sequence from one genomic region to another) or retroposition. While DNAbased duplications are often tandem (Thornton 2003), retroposed genes most often move to a new genomic environment, where they must acquire new regulatory elements or risk becoming processed pseudogenes, (Kaessmann et al., 2009). Different isoforms of the genes involved in phototransduction are expressed in vertebrate rod and cone photoreceptors, providing a unique example of parallel evolution via gene duplication (Lamb et al. 2018).

The second mechanism is the alteration of existing gene structures. A new gene structure can be generated by modifying existing exons or domains. Gilbert (1978) proposed that exons and domains could be recombined to produce new chimeric genes. In addition, retroposed sequences may jump into or near existing genes and recruit existing exons, or to be recruited into an existing coding sequence, (Zhang et al., 2009). Xue et al., (2003) found that the Epstein-
Barr virus contains an early gene that undergoes frequent frameshifts, probably to combat host immunity. In addition, divergence in alternative splicing patterns between duplicate genes can generate distinct transcripts that produce noncoding RNA or polypeptides with slightly or entirely different functions and rapidly alter duplicate gene structures and functions, (Zhang et al., 2010, Zhou et al., 2011).

The third mechanism is the De novo gene. New gene structures may arise from previously noncoding DNA. Chen et al., (1997) were the first to show that antifreeze protein, which binds and halt the growth of ice crystals in the blood of some polar fishes, was created by amplification of microsatellite DNA.

Since then a number of de novo genes originating from non-coding regions have been identified in humans, (Xie et al., 2012). Another origin of the de novo gene is the horizontal gene transfer (HGT), whereas the exchange of genes between genomes from distantly related taxa can immediately add new genes and functions in a genome. HGT is a major mechanism for the addition of new genes to prokaryotic genomes (Koonin et al., 2001), but has 
also been reported in a number of eukaryotic organisms including plants (Yoshida et al., 2010), insects (Moran et al., 2010), and fungi (Hall et al., 2005). Bedhomme et al., (2019) report a central role of HGT in fuelling evolution as a powerful mechanism promoting rapid, often dramatic genotypic and phenotypic changes. The profound reshaping of the pre-existing geno/phenotype allows the recipient bacteria to explore new ways of functioning, far beyond the mere acquisition of a novel function.

Host-parasite interaction is one type of relationship usually pointed out in the literature that could potentially increase the probability of the horizontal transfer between species, because the species involved in such relationships are generally in close contact. Transposable elements, which are wellknown genomic DNA, are DNA entities that tend to be involved in horizontal transfer due to their ability to mobilize between different genomic locations (Ortiz et al., 2014). The movement of RNAs between cells of a single plant is well documented. Kim et al. (2014) sequenced transcriptomes of Cuscuta growing on Arabidopsis and tomato hosts to characterize mRNA transfer between species and found that mRNA move in high numbers and in a bidirectional manner. These findings demonstrate that parasitic plants can exchange large proportions of their transcriptomes with hosts, providing potential mechanisms for RNA-based interactions between species and horizontal gene transfer. Feng et al. (2014) found and suggest that sequence diversity of tRNA-linked STR in E. nuttalli occurs with relatively high frequency and might be a marker of the geographical distribution of host rhesus macaques, even in a limited area. This result showed the effect of geographical variation on the diversity of tRNA or genetic materials.

The fourth mechanism for the production of new genes is non-coding RNAs. Not all new genes code for proteins. Non-coding RNAs were found to play an important role in neuronal functions in the early 1990s (Toll-Riera, et al., 1993). Dai et al., (2008) showed that a new long non-coding RNA influences courtship behavior in D. melanogaster.

The fifth mechanism is Transposable Elements (TE). A transposable element (TE, transposon, or jumping gene) is a DNA sequence that can change its position within a genome, sometimes creating or reversing mutations and altering the cell's genetic identity and genome size (Bourque et al 2018). Transposable elements represent one of several types of mobile genetic elements (Fig 4). TEs are assigned to one of two classes according to their mechanism of transposition, which can be described as either copy and paste (Class I TEs) or cut and paste (Class II TEs). (Kapitonov and 2008). Retrotransposon Class I TEs are copied in two stages: first, they are transcribed from DNA to RNA, and the RNA produced is then reverse transcribed to DNA. This copied DNA is then inserted back into the genome at a new position. The reverse transcription step is catalyzed by a reverse transcriptase, which is often encoded by the TE itself. The characteristics of retrotransposons are similar to retroviruses, such as HIV.

Retrotransposons are commonly grouped into three main orders: Retrotransposons, with long terminal repeats (LTRs), which encode reverse transcriptase, similar to retroviruses. Retroposons, long interspersed nuclear elements (LINEs, LINE-1s, or L1s), which encode reverse transcriptase but lack LTRs, and are transcribed by RNA polymerase II. Short interspersed nuclear elements (SINEs) do not encode reverse transcriptase and are transcribed by RNA polymerase III

(Retroviruses can also be considered TEs. For example, after the conversion of retroviral RNA into DNA inside a host cell, the newly produced retroviral DNA is integrated into the genome of the host cell. These integrated DNAs are termed proviruses. A provirus is a specialized form of eukaryotic retrotransposon, which can produce RNA intermediates that may leave the host cell and infect 
other cells. The transposition cycle of retroviruses has similarities to that of prokaryotic TEs, suggesting a distant relationship between the two.)

DNA transposes are the structure of DNA transposons (Mariner type). Two inverted tandem repeats (TIR) flank the transposase gene. Two short tandem site duplications (TSD) are present on both sides of the insert. The mechanism of transposition: Two transposases recognize and bind to TIR sequences, join together, and promote DNA doublestrand cleavage. The DNA-transposase complex then inserts its DNA cargo at specific DNA motifs elsewhere in the genome, creating short TSDs upon integration

The cut-and-paste transposition mechanism of class II TEs does not involve an RNA intermediate. The transpositions are catalyzed by several transposase enzymes. Some transposases nonspecifically bind to any target site in DNA, whereas others bind to specific target sequences. The transposase makes a staggered cut at the target site producing sticky ends, cuts out the DNA transposon, and ligates it into the target site. A DNA polymerase fills in the resulting gaps from the sticky ends and DNA ligase closes the sugar-phosphate backbone. This results in target site duplication and the insertion sites of DNA transposons may be identified by short direct repeats (a staggered cut in the target DNA filled by DNA polymerase) followed by inverted repeats (which are important for the TE excision by transposase). Cut-and-paste TEs may be duplicated if their transposition takes place during the $\mathrm{S}$ phase of the cell cycle when a donor site has already been replicated but a target site has not yet been replicated. Such duplications at the target site can result in gene duplication, which plays an important role in genomic evolution. Not all DNA transposons transpose through the cut-and-paste mechanism. In some cases, a replicative transposition is observed in which a transposon replicates itself to a new target site (e.g. helitron).

Class II TEs comprise less than $2 \%$ of the human genome, making the rest Class I. TEs are found in almost all life forms, and the scientific community is still exploring their evolution and their effect on genome evolution. It is unclear whether TEs originated in the last universal common ancestor, arose independently multiple times, or arose once and then spread to other kingdoms by horizontal gene transfer. (]Kidwell, 1992) While some TEs confer benefits on their hosts, most are regarded as selfish DNA parasites. In this way, they are similar to viruses. Various viruses and TEs also share features in their genome structures and biochemical abilities, leading to speculation that they share a common ancestor. (Villarreal (2005).

The genomic DNA is dynamic and not static, this proofed by transposable elements and horizontal gene transfer between intimate contact. TEs can mediate gene recombination by carrying coding sequences from one part of the genome to another (Yang et al., 2008). In addition, TEs were found to be a source of micro-RNAs, major components of posttranscriptional regulation of expression (Wang et al., 2012). Mobile elements are DNA sequences that can change their position (retrotranspose) with the genome. It has long been thought that neuronal genomes are invariable; however recent studies have demonstrated that mobile elements actively retrotranspose during neurogenesis, thereby creating genomic diversity between neurons. In addition, mounting data demonstrate that mobile elements are misregulated in certain neurological disorders, including Rett syndrome and schizophrenia (Erwin et al., 2014). Transposable elements have an ongoing, largely parasitic interaction with their host. Hellen and Brookfield (2013) examined the sequence divergence between class II DNA transposons from mammalian genomes. They reported that these sequences undergo a continuous process of turnover, keeping a family as an integrated whole, as members of the family are continually created and lost. Gifford et al. (2013) reported that TEs play an important role in somatic tissues and evolution. 'Transposable elements have made major evolutionary impacts on the creation of primate-specific and human-specific 
genomic regulatory loci and species-specific genomic regulatory networks (GRNs). Molecular and genetic definitions of human-specific changes to GRNs contributing to the development of unique to human phenotypes remain a highly significant challenge. Collectively, analyses reveal critical evolutionary contributions of transposable elements and distal enhancers to the creation of thousands of primate- and human-specific elements of a chromatin folding code, which defines the 3D context of interphase chromatin both restricting and facilitating biological functions of GRNs, (Glinsky, 2018).

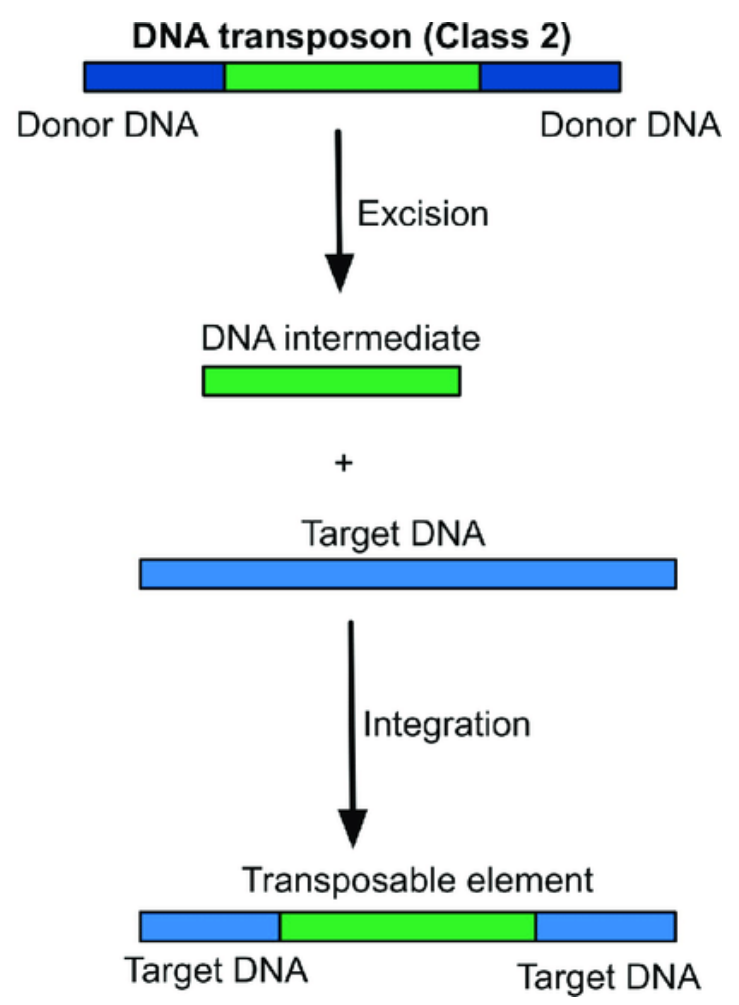

Fig. (4) types of Transposable elements

\section{Viruses and evolution}

Viruses consider the main source for evolution through integration into the genome of organisms from bacteria to humans. About $5 \%$ of the human genome sequence is composed of the remains of retroviruses that over millions of years have integrated into the chromosomes of egg and /or sperm precursor cells. There are indications that the protein expression of these viruses is higher in some diseases. (Marchi et al., 2014). Human papillomavirus (HPV) integration is a key genetic event in cervical carcinogenesis. By conducting whole-genome sequencing and high throughput viral integration detection $\mathrm{Hu}$ et al., (2015) identified 3.667 HPV integration breakpoints in 26 cervical intraepithelial neoplasia. Moreover, the microhomologous sequence between the human and HPV genomes was significantly enriched near integration breakpoints, indicating that fusion between viral and human DNA may have occurred by microhomology-mediated 
DNA repair pathways. (Hu et al., 2015). Human papillomavirus (HPV) integration within the E2 gene has been proposed as a critical event in cervical carcinogenesis. Radiation therapy caused an eightfold increase in the risk of HPV16 genome disruption. The integration status is influenced by the irradiation modalities, interestingly E2disruption being found widely after radiotherapy treatments with a total fractioned dose of $50 \mathrm{~Gy}$. (Kahla et al., 2014).

Approximately $1 \%$ of the human population inherits a chromosomally integrated copy of human herpesvirus 6 (C1-HHV-6). Huang et al. (2013) detected extra-chromosomal circular HHV-6 molecules and they found that truncated C1-HHV-6 and extra-chromosomal circular molecules are likely reciprocal products that arise through excision of telomere-loop (t-loop) formed within the CI-HHV-6 genome. After the release of viral sequences from human telomere as circular molecules, some of which have the potential to become fully functioning viruses (Huang et al. 2013)

Integration of the viral DNA into host chromosomes was found in most of the hepatitis B virus (HBV)- related hepatocellular carcinomas (HCCs). HBV integration favored chromosome 17 and preferentially integrated into human transcript units. Ding et al. (2012) identified 8 genes that were recurrent target genes by HBV integration including fibronectin 1 (FN 1) and telomerase reverse transcriptase (TERT 1), two known recurrent target genes, and additional novel target genes such as the SMAD family member 5 (SMAD 5), phosphatase and actin regulator 4 (PHACTR4), and RNA binding protein fox-1 homolog (G. elegance) 1 (RBFOX1). Moreover, additional fourteen recurrent HBV target genes were identified by Ding et al., (2012). Jacobs et al. (2014) reported that throughout evolution primate genomes have been modified by waves of retrotransposon insertion.

Retroviral replication proceeds through an obligate integrated DNA provirus making retroviral vectors attractive vehicles for human gene -therapy. Though most of the host cell genome is available for integration, the process of integration site selection is not random. Lentiviruses including HIV-1 preferentially integrate within the bodies of active genes, whereas the prototypical gammaretrovirus Moloney murine leukemia virus (MoMLV) favors strong enhancers and active genes promoter, (Kvaratskhelia et al., 2014).

Hepatocellular carcinoma (HCC) is a cancer of substantial morphologic, genetic, and phenotypic diversity. HBV integrations, indicating that $\mathrm{HBV}$ integration is an early driver event and remains extremely stable during tumor progression. Diverse modes of clonal evolution in HBV-related hepatocellular carcinoma revealed by single-cell genome sequencing, (Duan et al., 2018). Gene duplication and aneuploidy trigger the rapid evolution of herbicide resistance in common Waterhemp. This is the first report of early events in aneuploidy triggered de novo chromosome integration by an as yet unknown mechanism, which may drive rapid adaptive evolution of herbicide resistance in crop common Waterhemp, (Koo et al., 2018).

\section{Bacteria and evolution}

Bacteria also, chair in the evolution through a transfer of genetic materials to its host. Natural competence for transformation is a developmental program that allows certain bacteria to take up free extracellular DNA from the environment and integrated this DNA into their genome. Thereby, natural transformation acts as a mode of horizontal gene transfer and impacts bacterial evolution. (Matzger and Blokesch, 2014).

Horizontal gene transfer (HGT) is a major driving force of bacterial evolution. The rapid exchange of genetic information mediated by HGT enables bacteria to adapt to new environmental niches, to spread harmful traits such as antibiotic resistance cassettes or pathogenicity island, and to maintain 
genome integrity, (Stokes and Gillings, 2011). Horizontal gene transfer describes the transmission of genetic material across species boundaries. HGT often occurs in microbic and eukaryotic genomes. However, the pathways by which HGTs occur in multicellular eukaryotes, especially in plants, are not well understood. Gao et al., (2014) systematically summarized more than ten possible pathways for HGT. The intimate contact which frequently occurs in parasitism, symbiosis, pathogen, epiphyte, entophyte, and grafting interactions could promote HGTs between two species. Besides these direct transfer methods, a gene can be exchanged with a vector as a bridge, possible vectors include pollen, fungi, bacteria, viruses, viroids, plasmids, transposons, and insects. HGT, especially when involving the horizontal transfer of transposable elements, is recognized as a significant force propelling genomic variation and biological innovation, playing an important functional and evolutionary role in both eukaryotic and prokaryotic genomes, (Gao et al., 2014). The virulent malaria parasite in humans has the most AT-biased eukaryotic genome. Here, I perform comparative genomic analyses of the most AT-rich eukaryotes sequenced to date and show that the avian malaria parasites Plasmodium gallinaceum, P. ashfordi, and P. relictum have the most extreme coding sequences in terms of AT-bias. This information enables a better understanding of genome evolution and raises the question of how certain organisms can prosper despite severe compositional constraints, (Videvall, 2018).

Wang et al., (2007) demonstrated intergenic natural genetic transformation between Escherichia coli and Bacillus subtilis at different growth phases. Inspection of the genomes of bacterial pathogens indicates that their pathogenic potential relies, at least in part, on the activity of different elements that have been acquired by horizontal gene transfer from other (usually unknown) microorganisms. Similarly, in the case of resistance to antibiotics, besides mutation- driven resistance, the incorporation of novel resistance genes is a widespread evolutionary procedure for the acquisition of this phenotype. Current information in the field supports the idea that most (if not all) genes acquired by horizontal gene transfer by bacterial pathogens and contributing to their virulence potential or antibiotic resistance originate in the environmental, (Martínez, 2018). Predatory bacteria attack and digest other bacteria and therefore may play a role in shaping microbial communities. By comparative genomics, we detected two regions of gene content difference that likely occurred via horizontal gene transfer events. Acquired genes encode functions such as modification of DNA, membrane synthesis, and regulation of gene expression. Understanding genome evolution and variation in predation phenotypes among predatory bacteria will inform their development as biocontrol agents and clarify how they impact microbial communities. (Enos 2018). About half of all bacteria carry genes for CRISPR-Cas adaptive immune systems ${ }^{1}$, which provide immunological memory by inserting short DNA sequences from phage and other parasitic DNA elements into CRISPR loci on the host genome. The biotic complexity of microbial communities in natural environments is an important driver of the evolution of CRISPR-Cas adaptive immunity, with key implications for bacterial fitness and virulence, (Alseth et al., 2019).

\section{RNA and evolution}

Short interspersed elements (SINEs) act as driving forces in genome evolution, (Schmitz, 2012). SINEs are short interspersed elements derived from cellular RNAs that repetitively retropose via RNA intermediates and integrate more or less randomly back into the genome. SINEs propagated almost entirely vertically within their host cells and, once established in the germline, are passed on from generation to generation. As non-autonomous elements, their reverse transcription (from RNA to cDNA) and genomic integration depends on the 
activity of the enzymatic machinery of autonomous retrotransposons, such as long interspersed elements (LISEs). SINEs are widely distributed in eukaryotes, but especially effectively propagated in mammalian species. More than a million Alu-SINE copies populate the human genome (approximately $13 \%$ of genomic space), and few master copies of them are still active. SINEs serve as beneficial building blocks for evolution, contributing to phenotypic heterogeneity and modifying gene regulatory networks, (Schmitz, 2012). They substantially expand the genome space and introduce structural variation to the genome. SINSEs have the potential to mutate genes, to alter gene expression, and generate new parts of genes. A balanced distribution and controlled activity of such properties is crucial to maintaining the organism's dynamic and thriving evolution, (Schmitz, 2012).

\section{Nutrition and micro-RNA}

Environment transfer to organisms through food (nutrition), drinking and air (respiration), all previous parameters have magnified effects on genetic materials producing variations of living organisms through induction of benefit or harmful mutations, or variation of gene expression or appears of de novo gene from non-coding DNA. Eating is an engagement with the world, that transfer our environment into our bodies (Pollan, 2006). Experimental study reported that micro-RNAs (miRNAs) from plants may control target genes in the consumer, (Zhang et al., 2012). Food-derived plant miRNA entered mammalian circulation naturally and achieved levels comparable to those of abundant endogenous extracellular miRNA. Plant micro-RNAs were detected not only in circulation, but also in all murine tissue types examined, and at copy numbers rivaling those of endogenous miRNAs. In the liver, some plant miRNAs were more abundant than let-7a. In the mouse, plant miRNA were said to downregulate at least one endogenous target in the liver, the low-density lipoprotein receptor adapter protein one 1 (LDLRAPI), within hours of dietary intake (Kenneth and Kendai, 2014)

Snow et al. (2013) reviewed non-dietary means of systemic xenomiRNA transfer. Organ or stem cell transplants, blood transfusions, pregnancy, and various states of parasitism may involve direct RNA transfer from one organism to another. Inhalation of atmospheric plant material, injection of plant-based drugs, and fluid exchange (e.g. through different sexual practices) could allow RNA transfer. Liu et al. (2018) reported that MicroRNAs (miRNAs) are a group of endogenous non-coding small RNAs frequently 21 nucleotides long. miRNAs act as negative regulators of their target genes through sequence-specific mRNA cleavage, translational repression, or chromatin modifications. Alterations of the expression of a miRNA or its targets often result in a variety of morphological and physiological abnormalities, suggesting the strong impact of miRNAs on plant development.

A different sort of extracellular RNA (exRNA)mediated communication may exist in some eukaryotes (Witwer et al., 2013). RNA molecules associated with several extracellular carriers, including lipoprotein (Vickers et al., 2011) and protein complexes (Turchinovich and Burwinkel, 2012), but extracellular vesicles (EV) have enveloped viruses and EV have been examined, (Wurdinger et al., 2012).

\section{Environmental DNA}

Environmental DNA (eDNA), i.e. DNA released in the environment by any living form, represents a formidable opportunity to gather high-throughput and standard information on the distribution of feeding habits of species. It has therefore great potential for applications in ecology and biodiversity management. Environmental DNA for biodiversity research and monitoring constitutes essential reading for all graduate students, researchers and practitioners who do not have a strong background in molecular genetics and who are willing to use eDNA 
approaches in ecology and biomonitoring. Environmental DNA (eDNA) offers a way to sample genetic material non-invasively without requiring visual observation. While eDNA has been trialed extensively as a biodiversity and biosecurity monitoring tool with a strong taxonomic focus, it has yet to be fully explored as a means for obtaining population genetic information, (Clare et al., 2019).

Gaines et al., (2019) reported the mechanisms of weed resistance for herbicide glyphosate, including herbicide sequestration in the vacuole, a rapid cell death response, nucleotide polymorphisms in the herbicide target (5-enolpyruvylshikimate-3phosphate synthase, EPSPS), and increased gene copy number of EPSPS. For this latter mechanism, two distinct molecular genetic mechanisms have been observed, a tandem duplication mechanism and a large extrachromosomal circular DNA (eccDNA) that is tethered to the chromosomes and passed to gametes at meiosis. Herbicide resistance can generate new insights into plant adaptation to contemporary environmental stress. Boron induced toxicity stress on Citrus roots. Huang et al., (2019) suggested that miR319 and miR171 play a pivotal role in Citrus adaptation to long-term B toxicity by targeting MYB and SCARECROW, respectively, both of which are responsible for root growth and development. Temperature stress is a major environmental factor affecting not only plant growth and development, but also fruit postharvest life and quality. Huang et al., (2019) suggested that miR319 and miR171 play a pivotal role in Citrus adaptation to long-term B toxicity by targeting MYB and SCARECROW, respectively, both of which are responsible for root growth and development. Methylation of genomic DNA can influence the transcription profile of an organism and may generate phenotypic diversity for rapid adaptation in a dynamic environment. M. HpyAXI is a type III DNA methyltransferase present in Helicobacter pylori and is upregulated at low $\mathrm{pH}$. This enzyme may alter the expression of critical genes to ensure the survival of this pathogen at low $\mathrm{pH}$ inside the human stomach. M.HpyAXI methylates the adenine in the target sequence (5'GCAG-3') and shows maximal activity at $\mathrm{pH}$ 5.5. (Narayanan et al., 2019). Can ecological changes impact somatic genome development? Vitali et al. (2019) answered and reported that environmentally induced developmental thermoplasticity contributes to genotypic diversification in Paramecium.

\section{Exosomes and evolution.}

Exosomes and microvesicles (MVs) are derived from endosomes and the plasma membrane, respectively. These extracellular vesicles (EVs) play a significant role in intercellular communication by serving as a carrier for the transfer of membrane and cytosolic proteins, lipids, and RNA between cells, (Raposo et al., 2013).

The release of exosomes occurs by the fusion of multivesicular bodies (MVBs) with the plasma membrane in various types of cells, (Simons et al., 2009; Thery et al., 2009). Exosomes have also been isolated from a variety of body fluids, such as blood, semen, saliva, plasma, urine, cerebrospinal fluid, epididymal fluid, amniotic fluid, malignant and pleural effusions of ascites, bronchoalveolar lavage fluid, synovial fluid, and breast milk, (Simpson et al., 2008; Properzi, 2013). Exosomes play a significant role in communication between tumors and their target cells (fig. 5). The release of exosomes is essential for events such as gene transfer and the targeting of therapeutic agents to specific cells, (Gurunathan et al., 2019). 


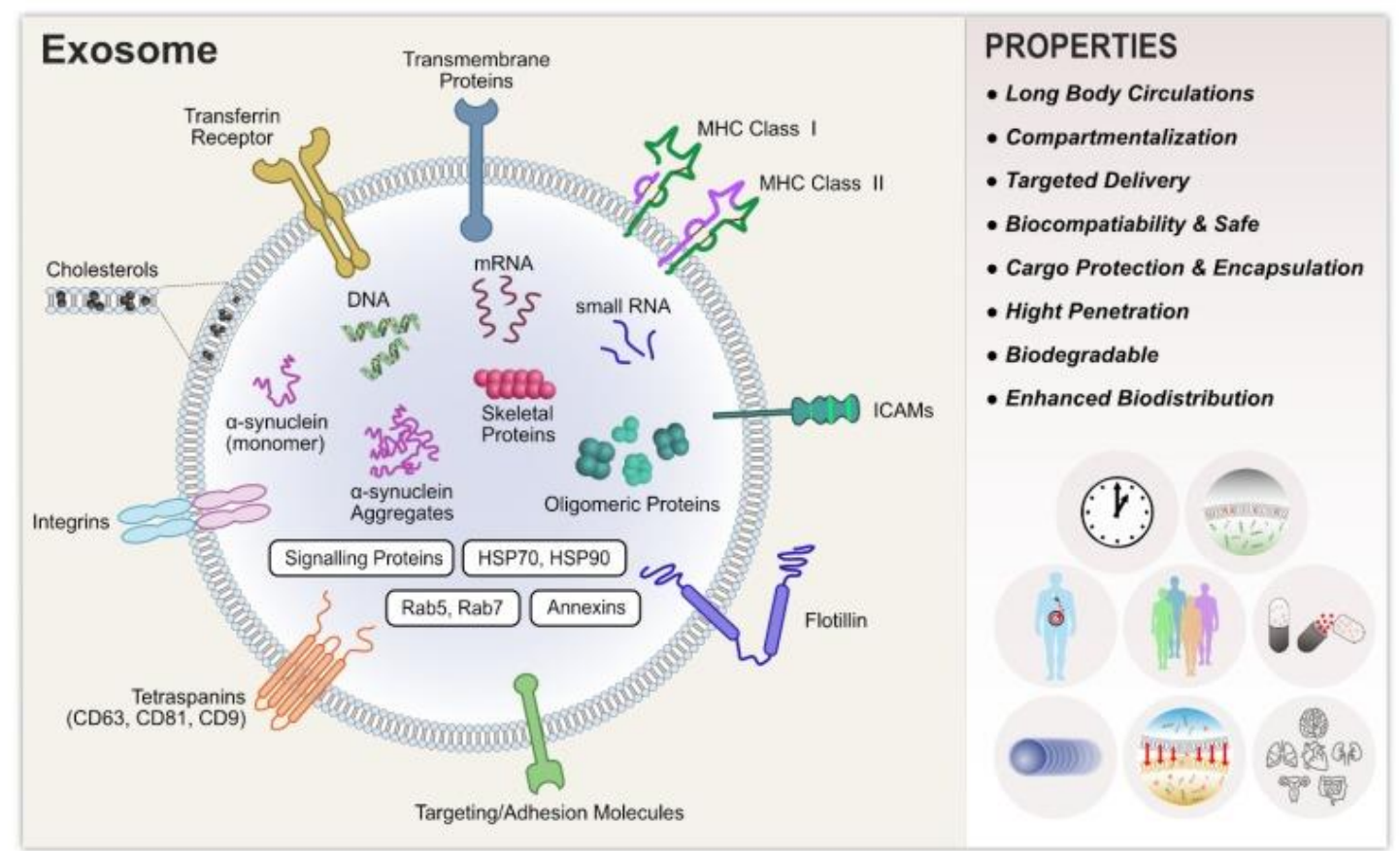

Fig. (5)Typical structure of exosomes, properties, and functional attribution of various biomolecules present in exosomes, (after Gurunathan et al., 2019).

Almost all bacteria, archaea, and eukaryotic cells shed extracellular vesicles either constitutively or in a regulated manner. These nanosized membrane vesicles are spherical, bilayered proteolipids that harbor specific subsets of proteins, DNAs, RNAs, and lipids. Some research has facilitated conceptual advancements in this emerging field that indicate that extracellular vesicles act as intercellular communicasomes by transferring signals to their target cell via surface ligands and delivering receptors and functional molecules. Almost all bacteria, archaea, and eukaryotic cells shed extracellular vesicles either constitutively or in a regulated manner. These nanosized membrane vesicles are spherical, bilayered proteolipids that harbor specific subsets of proteins, DNAs, RNAs, and lipids. Recent research has facilitated conceptual advancements in this emerging field that indicate that extracellular vesicles act as intercellular communicasomes by transferring signals to their target cell via surface ligands and delivering receptors and functional molecules. Choi et al.,
(2015). Extracellular vesicles (EVs) have emerged as a ubiquitous mechanism for transferring information between cells and organisms across all three kingdoms of life. In addition to their roles in normal physiology, vesicles also transport molecules from pathogens to hosts and can spread antigens as well as infectious agents. Although initially described in the host-pathogen context for their functions in immune surveillance, vesicles enable multiple modes of communication by, and between, parasites, (Coakley et al., 2015). Tumor-secreted extracellular vesicles (EVs) are critical mediators of intercellular communication between tumor cells and stromal cells in local and distant microenvironments. Accordingly, EVs play an essential role in both primary tumor growth and metastatic evolution. EVs orchestrate multiple systemic pathophysiological processes, such as coagulation, vascular leakiness, and reprogramming of stromal recipient cells to support pre-metastatic niche formation and subsequent metastasis. (Becker et al., 2016)

\section{Polymorphism and stress}


Any stress on any organism leads to polymorphism for adaptation. Age-related factors including oxidative stress play an important role in prostate carcinogenesis. Zhang et al., (2019) hypothesized that germline single-nucleotide polymorphisms (SNPs) in oxidative stress pathway are associated with prostate cancer $(\mathrm{PCa})$ risk. One SNP in the MAPK14 (rs851023) was significantly associated with incident $\mathrm{PCa}$ risk. Compared to men carrying two copies of allele $\mathrm{A}$, the presence of one or two copies of the $G$ allele was associated with decreased risk of PCa, (Zhang et al., 2019).

Agrichemical contamination can provoke evolutionary responses in freshwater populations. It is a particularly relevant issue in semi-arid regions due to the sensitivity of endemic species to pollutants and to interactions with temperature stress. A genome-wide approach was used and analyzed 2056 single nucleotide polymorphisms (SNPs) loci in 551 individuals from all sites. Our results reveal that A. Torrens is sensitive to pesticide exposure, but that a high gene flow may confer resilience to contamination, (Gouin et al., 2019) We developed in our lab electrophoretic pattern of nucleic acid technique, which is based on gently squeezing of solid tissue with blue tips and directly run in electrophoresis. This technique reflects the state of DNA and RNA without any technical or mechanical degradation. Surprisingly, we detected RNA less than 50 bp we predict that this RNA may be microRNA (Fig. 6). The technique of sister chromatid exchange (SCE) reflects the mutation and instability of the genome (Fig. 7,8,9) by increasing the rate of frequency of SCE than the normal rate. We observed some environmental pollution and drugs increased this rate, this reflects the effect of environmental pollution for increasing the rate of transfer or movement of transposable elements and induction of variation in the somatic or germinal genome. Chromosomal instability is a hallmark of cancer that results from ongoing errors in chromosome segregation during mitosis. chromosomal instability is a major driver of tumor evolution, its role in metastasis has been established. Chromosomal instability drives metastasis through a cytosolic DNA response, (Bakhoum, 2018). We found individual variation in one species of Artemia sp. And eel Anguilla anguilla using haplotype technique, (Fig. 10. Recently, we detect transverse of DNA from person to another through check hand (unpublished data) Fig. 11.

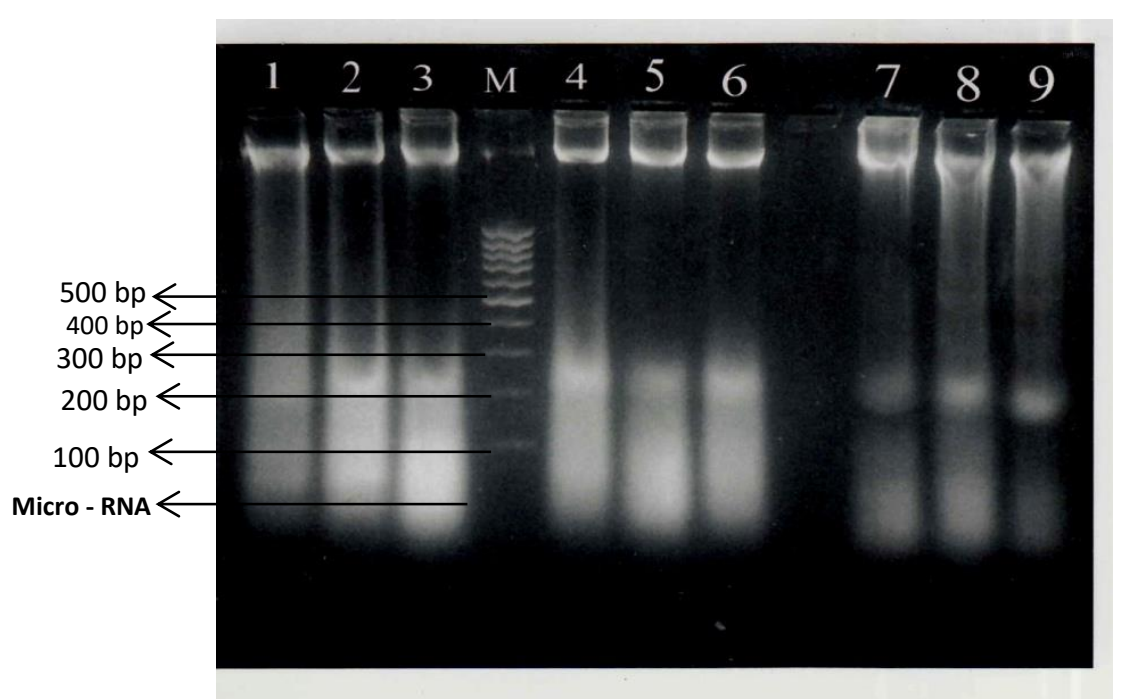

Fig. (6) Micro- RNA less than 100 bp (after Hassab El-Nabi, 2004) 


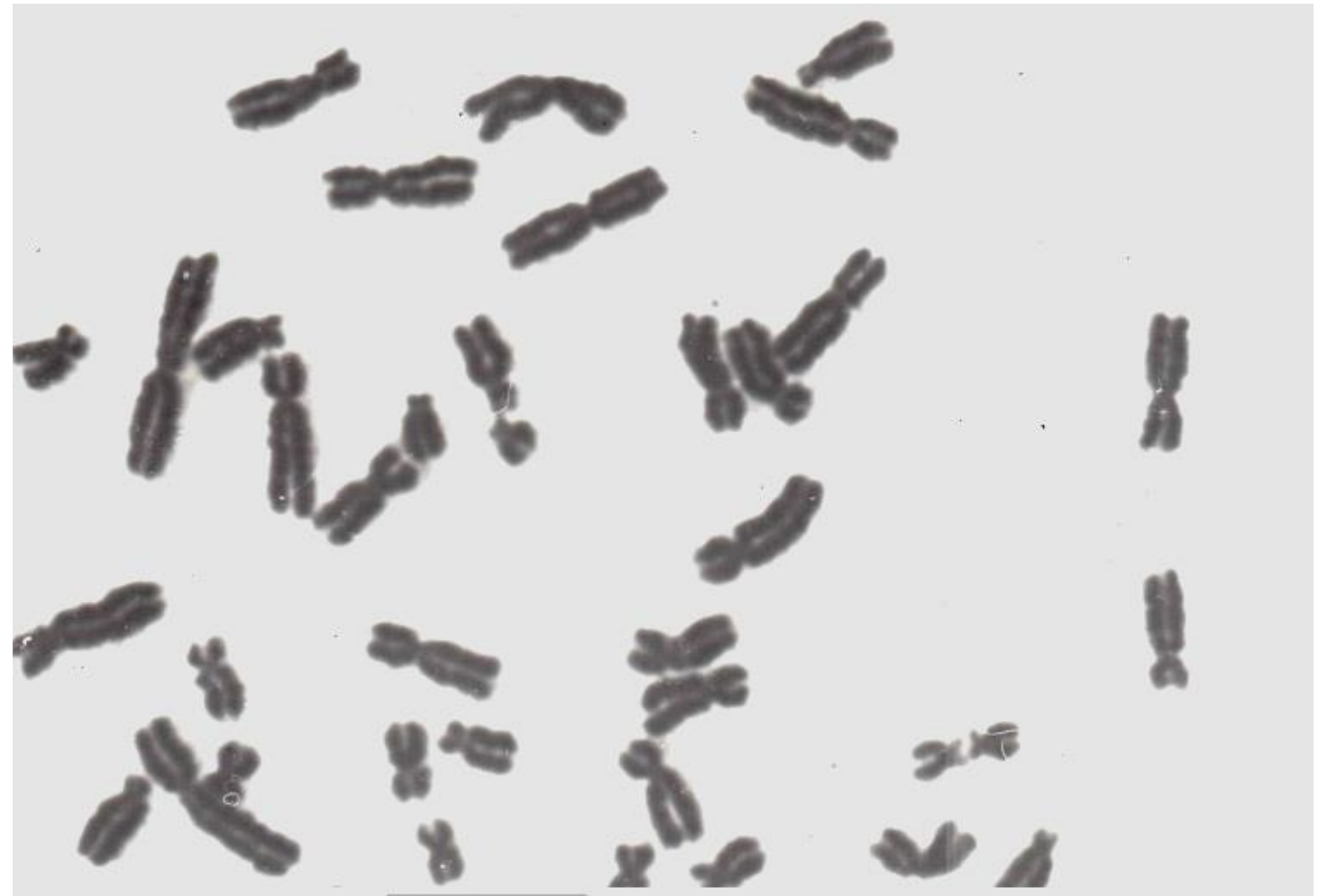

Fig. (7) Normal human metaphase (after Hassab El-Nabi, 1994)

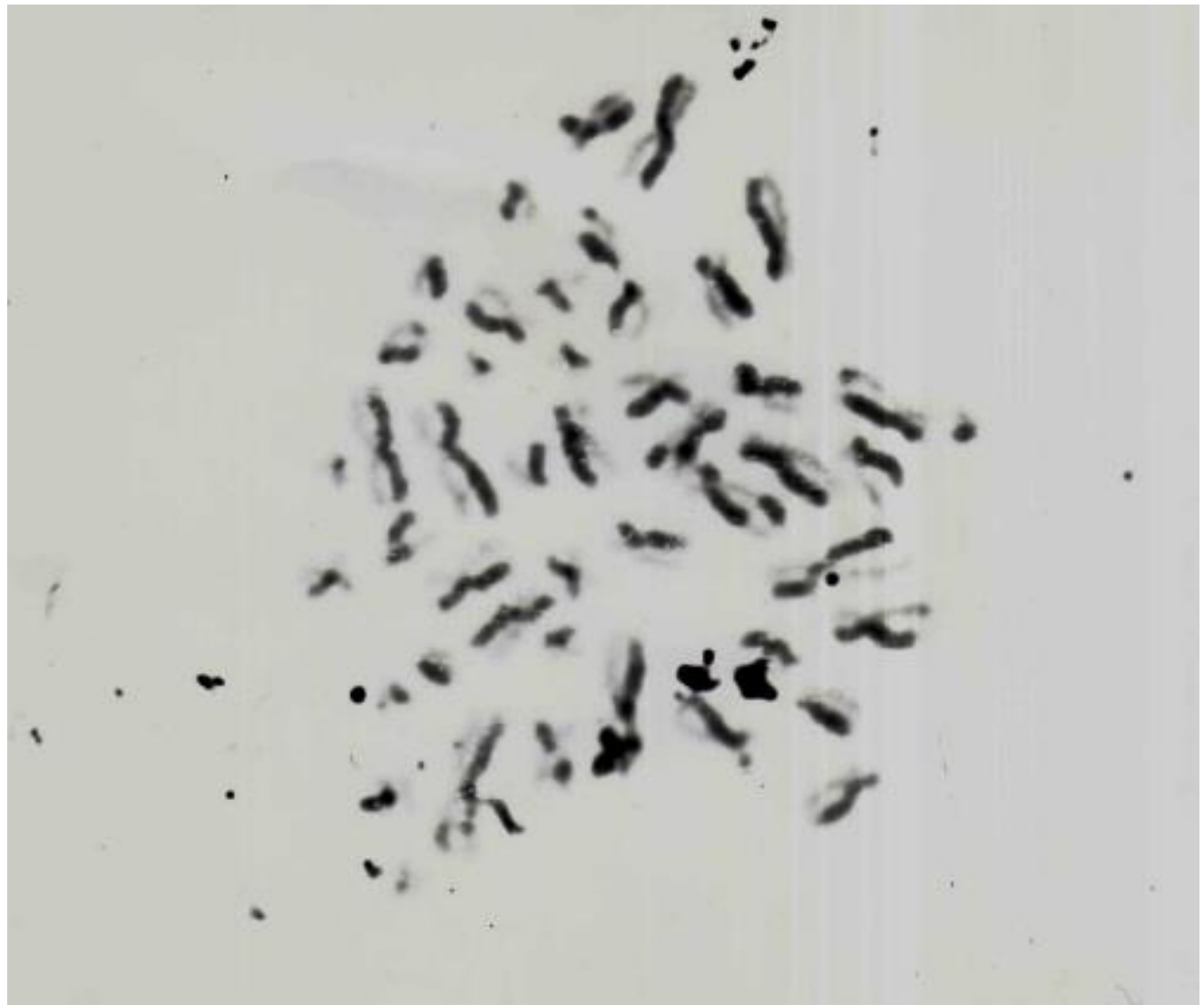

Fig. (8) Sister chromatid exchanges (SCE) in control human metaphase (after Hassab El-Nabi, 1994) 


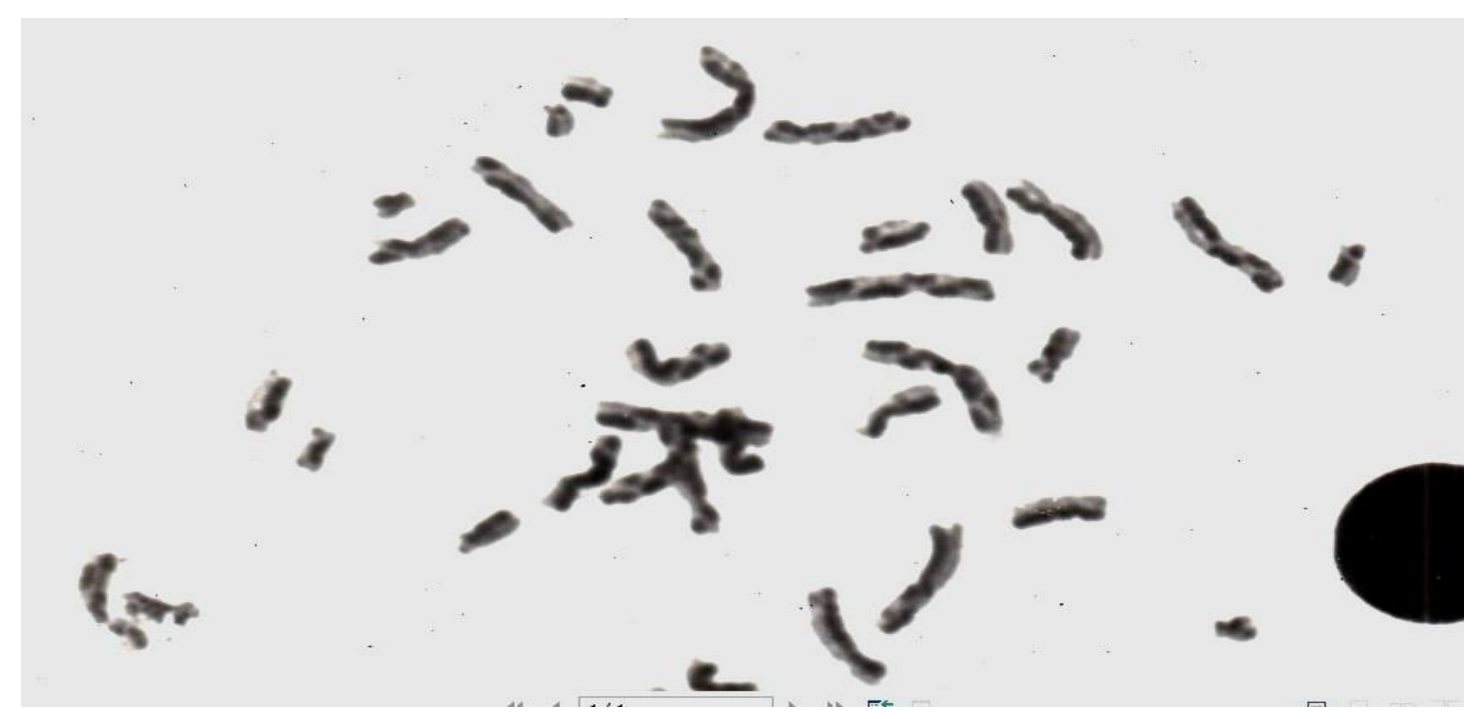

Fig. (9) Sister chromatid exchanges (SCE) in treated human metaphase with mitomycin C, (after Hassab El-Nabi, 1994).

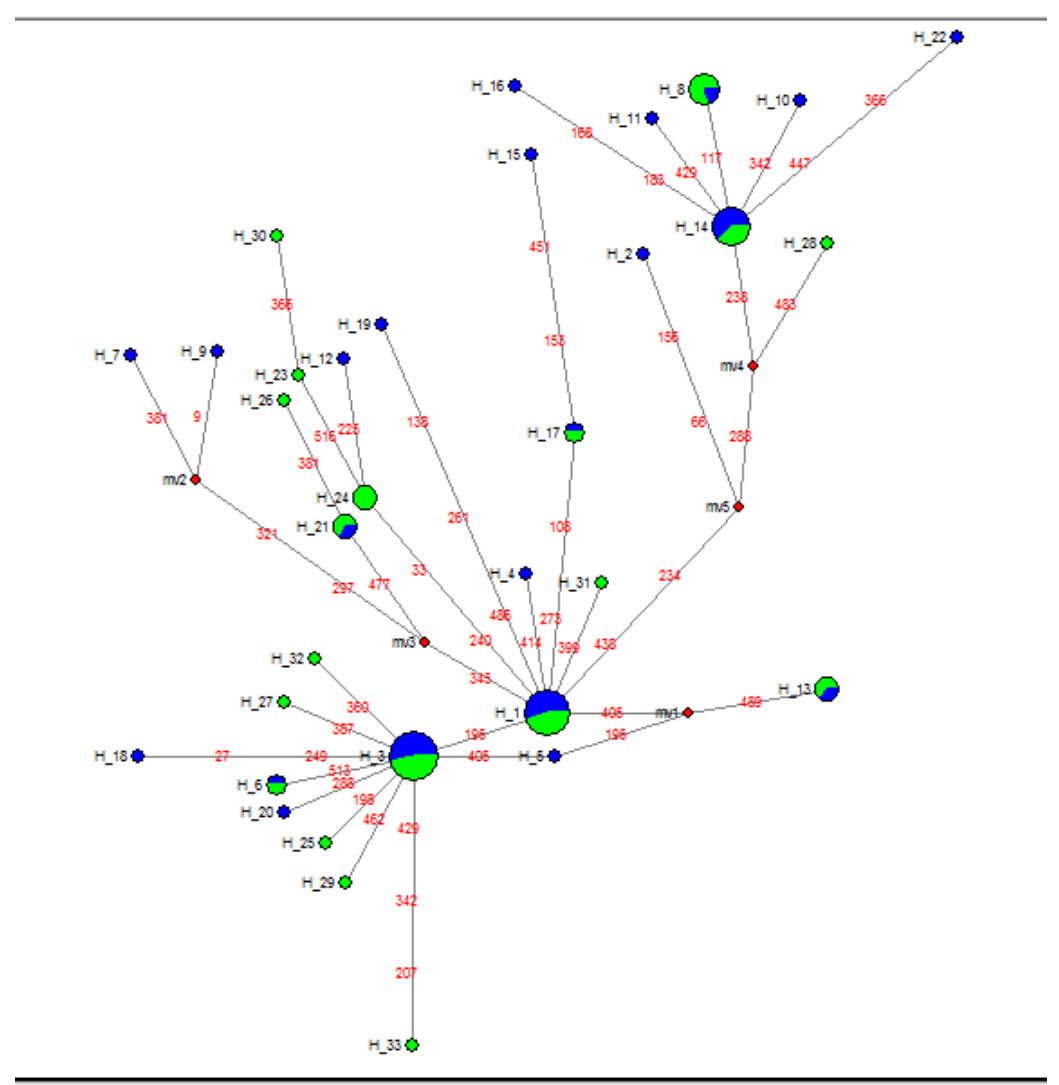

Fig. (10) Different haplotype of eel Anguilla anguilla (after Hassb El-Nabi et al., 2016) 


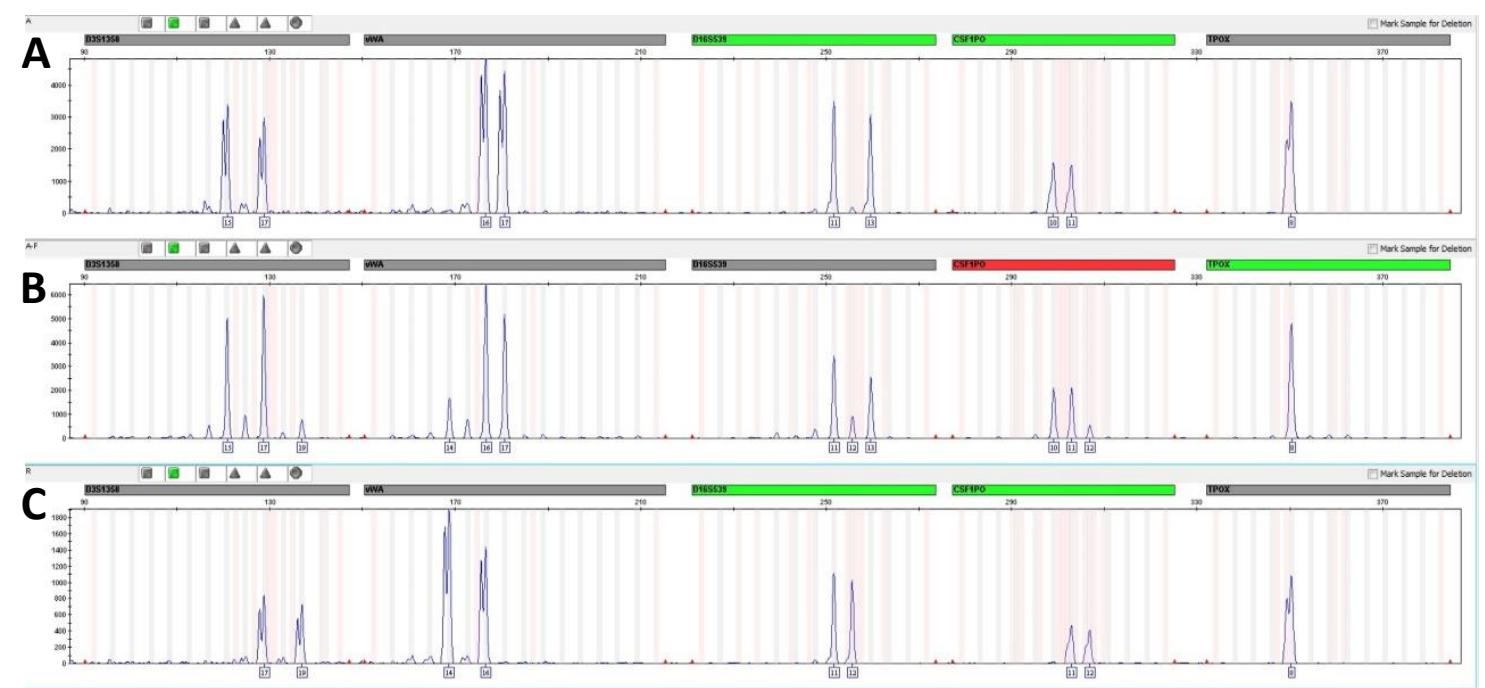

Figure (11): A comparison of the electropherogram of Blue and Green dyes for mixed STRs genotype resulted from check hands between two persons (A and C), that appeared in sample (B).

**Amplification products were separated on an Applied Biosystems ${ }^{\circledR} 3500$ Genetic Analyzer using a $3 \mathrm{kV}, 5$-second injection as described in the PowerPlex ${ }^{\circledR}$ Y23 System Technical Manual TMD035.

\section{References}

Alseth EO, Pursey E, Luján AM, McLeod I, Rollie C, Westra ER. (2019): Bacterial biodiversity drives the evolution of CRISPR-based phage resistance. Nature. Oct; 574(7779):549-552. doi: 10.1038/s41586-019-1662-9. Epub 2019 Oct 23.

Arroyo J.D., Chevillet J. R., Kroh E. M., Ruf I. K., et al., (2011): Argonaute2 complexes carry a population of circulating microRNAs independent of vesicles in human plasma. Proc Natl Acad Sci USA. 2011; 108: 5003-8.

Bakhoum SF, Ngo B, Laughney AM, Cavallo

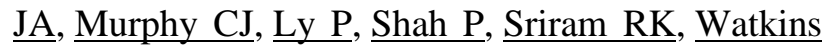
TBK, Taunk NK, Duran M, Pauli C, Shaw C, Chadalavada K, , Genovese G, Venkatesan

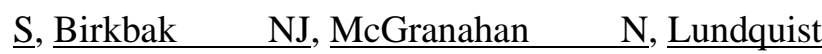
$\underline{M}$, LaPlant Q, Healey JH, Elemento O, Chung $\underline{\mathrm{CH}}, \underline{\text { Lee } \quad \mathrm{NY}}$, Imielenski $\mathrm{M}, \underline{\text { Nanjangud } \mathrm{G}}, \underline{\text { Pe'er }}$ D, Cleveland DW, Powell SN, Lammerding J, Swanton C, Cantley LC. Chromosomal instability drives metastasis through a (2018): cytosolic DNA response. Nature. Jan 17. doi: 10.1038/nature25432.

Becker A, Thakur BK, Weiss JM, Kim $\underline{\text { HS}}, \underline{\text { Peinado H}}$, Lyden D ; $2016 \quad$ Extracellular
Vesicles in Cancer: Cell-to-Cell Mediators of Metastasis.Cancer Cell.; Dec12;30(6):836-848. doi: 10.1016/j.ccell.2016.10.009.

Bedhomme S, Amorós-Moya D, Valero LM, Bonifaci N, Pujana MÀ, Bravo IG (2019): Evolutionary Changes after Translational Challenges Imposed by Horizontal Gene Transfer. Genome Biol Evol. 2019 Mar 1; 11(3):814-831. doi: 10.1093/gbe/evz031.

Bourque G, Burns KH, Gehring M, Gorbunova V, Seluanov A, Hammell M, Imbeault M, Izsvák Z, Levin HL, Macfarlan TS, Mager DL, Feschotte C (November 2018). "Ten things you should know about transposable elements". Genome Biology. 19 (1): 199 . doi: 10.1186/s13059-018-1577-z. PMC 6240941. PMID 30454069

Chen, L., DeVries A. L. and Cheng C.H. (1997): Evolution of antifreeze glycoprotein gene from a trypsinogen gene in Antarctic notothenioid fish. Proceedings of the National Academy of Sciences of the United States of America. ; 94(8): 3811-3816

$\underline{\text { Choi }}^{1}{ }^{1},{\underline{\operatorname{Kim}} \mathrm{DK}^{1}}^{1}, \underline{\operatorname{Kim}}_{\mathrm{YK}^{1}}$, Gho $\underline{\mathrm{YS}}^{1}$ (2015) Proteomics of extracellular vesicles: 
Exosomes and ectosomes, Mass Spectrom Rev. JulAug;34(4):474-90. doi: 10.1002/mas.21420. Epub 2014 Jan 14.

\section{Clare I.M. Adams, Neil J.} Gemmell, Gert-Jan Jeunen, Michael Bunce, Miles D. Lamare andHelen R. Taylor . (2019): Beyond Biodiversity: Can Environmental DNA (eDNA) Cut It as a Population Genetics Tool?. Genes, 10(3), 192; https://doi.org/10.3390/genes10030192

Coakley $\mathrm{G}^{1}$, Maizels RM ${ }^{1}$, Buck AH (2015): Exosomes and Other Extracellular Vesicles: The New Communicators in Parasite Infections. Trends Parasitol.; Oct;31(10):477-489. doi: 10.1016/j.pt.2015.06.009.

Dai H., Chen, Y., Chen S. Mao Q., Kennedy D.; Landback, P.;Eyre-Walker A.;Du, W. and Long M. (2008): The evolution of courtship behaviors through the origination of a new gene in Drosophila. Proceedings of the National Academy of Sciences of the United States of America. 105(21); 7478-7483.

Darwin Charles (1859) The origin of species by means of natural selection, or the preservation of favoured races in the struggle for live By Charles Darwin, AM, fellow of the Royal Geoijogica 11, Linna; AN, ETC, Societies ; author of Journal of researches during XI.M,s. Beaoleei voyage round the world , London: John Murray, Albemarle street. 1859. London: printed XP W. Cwwes and Sonu, Stamford Street. And Cfiaring Cross

Ding D., Lou X., Hua D., Yu W., Li L., Wang J., Gao F., Zhao N., Ren G., Li 1. and Lin B. (2012): Recurrent targeted genes of hepatitis B virus in the liver cancer genomes identified by a next-generation sequencing-based approach. PLoS Genet. 8(12): e1003065.

Duan M, Hao J, Cui S, Worthley DL, Zhang S, Wang Z, Shi J, Liu L, Wang X, Ke A, Cao Y, Xi R, Zhang X, Zhou J, Fan J, Li C, Gao Q' (2018): Diverse modes of clonal evolution in HBV-related hepatocellular carcinoma revealed by single-cell genome sequencing . Cell Res. Jan 12. doi: 10.1038/cr.2018.11.

Edvotec (2014): The genesis of new genes; part 2: posted on May 5, 2014 by drbrianell Enos
BG, Anthony MK, DeGiorgis JA, Williams LE. (2018): Prey Range and Genome Evolution of Halobacteriovorax marinus Predatory Bacteria from an Estuary. mSphere. Jan 10;3(1). pii: e00508-17. doi: 10.1128/mSphere.00508-17. eCollection 2018 Jan-Feb.

Erwin J. A., Marchetto M. C. and Gage F. H. (2014): Mobile DNA elements in the generation of diversity and complexity in the brain. Nat. Rev. Neurosci. 15(8): 497-506.

Gao C., Ren X., Mason A. S., Liu H., Xiao M., Li J. and Fu D. (2014): Horzontal gene transfer in plants. Funct. Integr. Genomics; 14(1): 23-29.

Gaines TA, Patterson EL, Neve P. (2019): Molecular mechanisms of adaptive evolution revealed by global selection for glyphosate resistance. New Phytol. Sep; 223(4):1770-1775. doi: 10.1111/nph.15858. Epub May 15.

Ghiselin, Michael T. (1994). "The Imaginary Lamarck: A Look at Bogus "History" in Schoolbooks". The Textbook Letter (SeptemberOctober 1994). Archivedfrom the original on 12 October 2000.

Gifford W. D., Pfaff S. L. and Macfarlan T. S. (2013): Transposable elements as genetic regulatory substrates in early development. Trends Cell Biol. 23(5): 218-226.

Glinsky GV. (2018): Contribution of transposable elements and distal enhancers to evolution of human-specific features of interphase chromatin architecture in embryonic stem cells. Chromosome Res. Jan 15. doi: 10.1007/s10577-0189571-6.

Gouin $\quad \mathrm{N}^{1}$, Bertin $\quad \mathrm{A}^{2}$, Espinosa $\quad \mathrm{MI}^{3}$, Snow $\mathrm{DD}^{4}$, Ali $\quad \mathrm{JM}^{5}$, Kolok $\quad \mathrm{AS}^{6} \quad$ 2019): Pesticide contamination drives adaptive genetic variation in the endemic mayfly Andesiops torrens within a semi-arid agricultural watershed of Chile. Environ Pollut. Sep 26; $255(\mathrm{Pt} \quad 2): 113099 . \quad$ doi: 10.1016/j.envpol.2019.113099. Gurunathan S, Kang M, Jeyaraj M, Qasim M, and Kim J (2019): Review of the Isolation, Characterization, Biological Function, and Multifarious Therapeutic 
Approaches of Exosomes. Cells. 2019 Apr; 8(4): 307.Published online $2019 \quad$ Apr 3. doi: 10.3390/cells 8040307

Kidwell MG (1992). "Horizontal transfer of $\mathrm{P}$ elements and other short inverted repeat transposons". Genetica. 86 (1-3): 275-86. doi:10.1007/BF00133726. PMID 1334912.

Hassab El-Nabi S.E., Mohammed-Geba K., and Saied M. (2016): Genetic population structure of eel Anguillo Anguilla in lack Burullus and Rachid estuary (in press)

Hassab El-Nabi, S. E. (2004): Molecular studies on the relationship between apoptosis and DNA damage induced by dexamethasone and flumox in liver and spleen of rat and human lymphocytes culture. J. Egypt. Ger. Soc. Zool. (45 C): Histology \& HistochemiStry, 175 - 202.

Hassab El-Nabi S.E, (1994): Genetic monitoring studies on selective environmental pollutants (pesticides) suspected to be mutagens to mammalian animals. Ph.D. Thesis ; Zoology departments, Faculty of Science, Menoufiya University

Hassab El-Nabi S.E. (2016) Gene evolution and diversity of living organisms theory. Journal of Bioscience and Applied Research , 2(2): 124-150

Hassab Elnabi S. E. (2020): New strategies for treatment of COVID-19 and evolution of SARSCoV-2 according to biodiversity and evolution theory. EGYPTIAN JOURNAL OF BASIC AND APPLIED SCIENCES. 2020, VOL. 7, NO. 1, 226232.

https://doi.org/10.1080/2314808X.2020.1789815

Hassab El-Nabi S.; Mohamed Elhiti; Mostafa ElSheekh: (2020) A new approach for COVID-19 treatment by micro-RNA. Medical Hypotheses; 2020. Oct; 143: 110203. Article | WHO COVID | ID: covidwho-720652.

\section{DOI: 10.1016/j.mehy.2020.110203}

Hecht M.M., Nitz N., Araujo P. F., Sousa A. O., Rosa Ade C., Gomes D. A., Leonardecz E. and Teixeira A. R. (2010): Inheritance of DNA transferred from American trypanosomes to human hosts. PLoS one; 5(2): e9181.
Hellen E. H. and Brookfield J. F. (2013): Transposable element invasions. Mob Genet Elements 3(1): e23920.

Hu Z., Zhu D., Wang W., Li W., Jia W.M Zeng X., Ding W., Yu L., Wang X., Wang L., Shen H., Zhang C., Liu H., Liu X., Zhao Y., Fang X., Li S. Chen W., Tang T., Fu A., Wang Z., Chen G., Gae Q., Li S., Xi L., Wang C., Liae S., Ma X., Wu P., Li K., Wang S., Zhou J., Wang J., Xu X., Wang H. and Ma D. (2015): Genome-wide profiling of HPV integration in cervical cancer identifies clustered genomic hot spots and a potential microhomologymediated integration mechanism. Nat. Genet.; 47(2): 158- 163.

Huang JH, Lin XJ, Zhang LY, Wang XD, Fan GC, Chen LS. (2019): MicroRNA Sequencing Revealed Citrus Adaptation to Long-Term Boron Toxicity through Modulation of Root Development by miR319 and miR171. Int J Mol Sci. 21;20 (6). pii: E1422. doi: 10.3390/ijms20061422.

Huang Y., Hidalgo-Bravo A. Zhang E., Cotton V. E., Mendez-Bermudez A., Wig G., Medina-Calzada Z., Neumann R., Jeffreys A. L., Winn B., Wilson J. F., Clark D. A., Dyer M. J. and Royle N. J. (2014): Human telomeres that carry an integrated copy of human herpesvirus 6 are often short and unstable, facilitating release of the viral genome from the chromosome. Nucleic Acids Res. ; 42(1): 315-27.

Huxley, T.H. 1860: "ART. VIII.-Darwin on the Origin of Species". Westminster Review (Book review). London: Baldwin, Cradock, and Joy. 17: 541-570. Retrieved 19 June 2008. What if the orbit of Darwinism should be a little too circular?

Jacobs F. M., Greenberg D., Nquyen N., Haeussler M., Ewing A. D., Katzman S., Paten B., Salam S. R. and Haussler D. (2014): an evolutionary arms race between KRAB zing-finger genes ZNF91193 and SVAlL1 retrotransposens. Nature; 516(7530): 242-5.

Kaessmann H , Vinckenbosch N, and Long M (2009): RNA-based gene duplication: mechanistic and evolutionary insights. Nature Reviews Genetics. 10(1): 19-31. 
Kahla S., Kochbati L., Maalei M. and Queslati R. (2014): Situation of HPV16 E2 gene status during radiotherapy treatment of cervical carcinoma. Asian Pac J. Cancer Prev. ; 15(6): 2869-73.

Kapitonov VV, Jurka J (May 2008). "A universal classification of eukaryotic transposable elements implemented in Repbase". Nature Reviews. Genetics. 9 (5): 411-2, author reply 414. doi:10.1038/nrg2165-c1. PMID 18421312

Kenneth W. Witwer and Kendal D. Hirschi (2014): Transfer and functional consequences of dietary microRNAs in vertebrates: Concepts in search of corroboration Bioessays.; 36(4): 394-406.

Kim G.,LeBlanc M. L., Wafula E. K., dePamphilis C. W. and Westwood J. H. (2014): Plant science, Genomic-scale exchange of Mrna between a parasitic plant and its host. Science, 15;345(6198) : 808-811.

$\underline{\text { Koo D } \mathrm{H}^{1}}$, Jugulam M$, \underline{\text { Putta } \mathrm{K}}, \underline{\text { Cuvaca I }}$ B, Peterson D, Currie R.S, Friebe B, Gill B. S. (2018): Gene duplication and aneuploidy trigger rapid evolution of herbicide resistance in common waterhemp. Plant Physiol. Jan 2. pii: pp.01668.2017. doi: 10.1104/pp.17.01668.

Kuraku S., Qiu H. and Meyer A. (2012): Horizontal transfers of $\mathrm{Tc} 1$ elements between teleost fishes and their vertebrate parasites, lampreys. Genome Biol. Evol.; 4(9): 929-936.

Kvaratskhelia M., Shama A., Larue R. C., Serrao E. and Engelman A. (2014): Molecular mechanisms of retroviral integration site. Nucleic acids Res.; 42(16): 10209-25.

Lamb TD, Patel HR, Chuah A, Hunt DM (2018) Evolution of the shut-off steps of vertebrate phototransduction. Open Biol. Jan;8(1). pii: 170232. doi: 10.1098/rsob.170232.

Weyrich LS ${ }^{1}$, Llamas B (2019): More arrows in the ancient DNA quiver: use of paleoepigenomes and paleomicrobiomes to investigate animal adaptation to environment. Mol Biol Evol. Oct 22. pii: msz231. doi: 10.1093/molbev/msz231.

Liu H, Yu H, Tang G, Huang T. (2018): Small but powerful: function of microRNAs in plant development. Plant Cell Rep. Jan 9. doi: 10.1007/s00299-017-2246-5.

Manyuan Long, Nicholas W. Vankuren, Sidi Chen and Maria D. Vibranovski (2013): New gene evolution: little did we know , Annu. Rev. Genet. 47; 307-333

Marchi E., Kanapin A., Magiorkinis G. and Belshaw R. (2014): Unfixed endogenous retroviral insertions in the human population. J. Virol.; 88(17): 9529-37.

Martínez J. L. (2018): Ecology and Evolution of chromosomal Gene Transfer between Environmental Microorganisms and Pathogens. Microbiol Spectr. Jan;6(1). doi: 10.1128/microbiolspec.MTBP-0006-2016.

Metzger L.C. and Blokesch M. (2014): Composition of the DNA-uptake complex of Vibrio cholera. Mob. Genet. Elements; 4(1): e28142.

Narayanan , N, Banerjee A, Jain D, Kulkarni DS, Sharma R, Nirwal S, Rao DN, Nair DT (2019): J Mol Biol. 16. pii: S0022-2836(19)30579-0. doi: 10.1016/j.jmb.2019.10.001. J Mol Biol. 2019 Oct 16. pii: S0022-2836(19)30579-0. doi: 10.1016/j.jmb.2019.10.001.).tramerization at low $\mathrm{pH}$ licenses DNA methylation activity of M.HpyAXI in the presence of acid stress. J Mol Biol. 2019 Oct 16. pii: S0022-2836(19)30579-0. doi: 10.1016/j.jmb.2019.10.001.

Ortiz M. F., Wallau G. L. , Graichen D. A. and Loreto E. L.(2014): An evaluation of the ecological relationship between Drosophila species and their parasitoid wasps as an opportunity for horizontal transposon transfer. Mol. Genet. Genomics. 290(1): 67-78.

Pollan M. (2006): The Omnivore's Dilemma: A Natural History of Four Meals. New York: Penguin Press; 2006.

Schmitz J. (2012): SINEs as driving forces in genome evolution. Genome Dyn. 7 : 92-107.

Sidi Chen, Benjamin H. Krinsky Manyuan Long (2013): Box 1: Mechanisms of new-gene origination; Nature Reviews Genetics; 14 645-660 doi: $10.1038 / \operatorname{nrg} 3521$ 
Snow Jw, Hale AE, Isaacs SK, Baggish AL, Chan . SY Ineffective Delivery of Diet-Derived microRNAs to Recipient Animal Organisms. RNA $\begin{array}{llll}\text { Biol. } \quad 2013 \quad J u l ; 10 \quad \text { (7):1107-16. doi: } & \end{array}$ 10.4161/rna.24909. Epub 2013 May 3.

Stokes H. W. and Gillings M. R. (2011): Gene flow, mobile genetic elements and the recruitment of antibiotic resistance genes into Gram-negative pathogens. FEMS Microbial Rev.; 35: 790-819.

Thornton K. R. (2003): Gene conversion and natural selection at duplicate loci in Drosophila melanogaster. University of Chicago.

Tiedge H.,Chen W. and Brosius J.(1993): Primary structure, neural-specific expression, and dendritic location of human BC200 RNA. The Journal of Neuroscience. 13: 2382-2390.

Toll-Riera M., Bosch N., Bellora N.,Castelo R., Armengol L., Estivill X.and Alba M. M. (2009): Origin of primate orphan genes: A comparative genomics approach. Molecular Biology and Evolution. 26(3): 603-612.

Turchinovich A. and Burwinkel B. (2012): Distinct AGO1 and AGO2 associated miRNA profiles in human cells and blood plasma. RNA Biol.; 9:1066-75.

Vickers K. C., Palmisano B.T., Shoucri B. M., Shamburek R.D., et al. (2011): MicroRNAs are transported in plasma and delivered to recipient cells by high-density lipoproteins. Nat Cell Biol.; 13: 42333. Videvall E. (2018): Plasmodium parasites of birds have the most AT-rich genes of eukaryotes. Microb Genom. Jan 23. doi: 10.1099/mgen.0.000150

Villarreal L (2005). Viruses and the Evolution of Life. Washington: ASM Press

Vitali $\quad V^{1}$, Hagen $\quad R^{1}$, Catania $\quad F^{1}(2019)$ : Environmentally induced plasticity of programmed DNA elimination boosts somatic variability in Paramecium tetraurelia. Genome Res. Oct; 29(10):1693-1704. doi: 10.1101/gr.245332.118. Epub 2019 Sep 23.

Witwer K. W., Buzas E. I., Bemis LT, Bora A, et al. Standardization of sample collection, isolation and analysis methods in extracellular vesicle research. J

Extracell

Vesicles.

2013;2 10.3402/jev.v2i0.20360.

Wurdinger T., Gatson N.N., Balaj L., Kaur B., et al.,(2012): Extracellular vesicles and their convergence with viral pathways. Adv Virol. 2012; 2012:767694.

Xie C., Zhang Y. Y., Chen J-Y., Liu C-J., Zhou W-Z., Li Y., Zhang M., Zhang R., Wei L. and Li CY (2012): Hominoid-specific De novo protein-coding genes originating from long non-coding RNA. PLoS genetics. 8(9): e1002942 [PubMed].Xue S., Jones M. D., Lu Q.,Middeldorp J. M. and Griffin B. E.(2003): Genetic diversity : Frameshift mechanisms alter coding of a gene (Epstein -Barr Virus LF3 gene) that contains multiple 102-base pair direct sequence repeats . Molecular and Cellular Biology. 23(6): 2192-2201.

Yang S., Arguello J. R., Li X., Ding Y., Zhou Q., Chen Y. and Zhang Y., et al., (2008): Repetitive element-mediated recompination as a mechanism for new gene origination in Drosophila. PLoS Genetics. 4 (1): e3. [PubMed].Yoshida S., Maruyama S., Nozaki H. and Shirasu K. (2010): Horizontal gene transfer by the parasitic plant striga hermonthica. Science. 328: 1128.

Zhang Z, Jiang D, Wang C, Garzotto M, Kopp $\underline{\mathrm{R}}$, Wilmot B, Thuillier $\mathrm{P}^{0}$, Dang A, Palma A, Farris PE, Shannon J (2019) : polymorphisms in oxidative stress pathway genes and prostate cancer risk. Cancer Causes Control. Oct 30. doi: 10.1007/s10552-019-01242-7. [Epub ahead of print]

Zhang L. , Hou D., Chen X., Li D., et al., (2012): Exogenous plant MIR168a specifically targets mammalian LDLRA P1: evidence of cross-kingdom regulation by microRNA. Cell Res.; 22: $107-$ 26. [PMC free article][PubMed]

Zhang P. G., Huang S. Z. Pin A-L and Adams K. L. (2010): Extensive divergence in alternative splicing patterns after gene and genome duplication during the evolutionary history of arsbidopsis. Molecular Biology and Evolution. 27 (7): 1686-1697.

Zhang Y., Lu S., Zhau S., Zheng X., Long M.and Wei L. (2009): Positive selection for the male 
functionality of a co-retroposed gene in the hominoids. BMC Evolutionary Biology. 9: 252.

Zhu H, Zhang Y, Tang R, Qu H, Duan X, Jiang $Y$ (2019): Banana sRNAome and degradome identify microRNAs functioning in differential responses to temperature stress. BMC Genomics. 2019 Jan 10;20(1):33. doi: 10.1186/s12864-018-5395-1.
Zhou R., Moshgabadi M. and Adams K. L.(2011): Extensive changes to alternative splicing patterns following allopolyploidy in natural and resynthesized polyploids. Proceeding of the National Academy of Sciences of the United States of America. 108(38): 16122-16127. 